\title{
Numerical study of contributions of shock wave and gas penetration toward induced rock damage during blasting
}

\author{
M. Lanari ${ }^{1}$ - A. Fakhimi ${ }^{1}$
}

Received: 20 February 2015 / Revised: 28 April 2015 / Accepted: 30 May 2015 / Published online: 9 June 2015 (C) OWZ 2015

\begin{abstract}
The authors present an improved version of continuum analysis $2 D$, a hybrid two-dimensional finite elementdiscrete element-smoothed particle program for modeling rock blasting. A modified formula governing the interaction of smoothed particles with discrete elements is presented, along with the results of numerical simulations involving detonations within jointed rock. PETN was modeled as the explosive, and Barre granite as the rock specimen. The borehole was simulated both with and without a thin copper lining. The purpose of the copper lining is to prevent gas from penetrating into the induced cracks within the rock, so that the shock wave's contribution toward rock damage can be separated from that of the gas penetration. The results suggest that majority of the cracks are formed due to the shock wave propagating within the rock, whereas the gas penetration mostly separates the already-formed rock fragments and pushes them apart.
\end{abstract}

Keywords Rock blasting - Shock wave - Gas flow . Bonded particles $\cdot$ Smoothed particle hydrodynamics $\cdot$ Rock damage

\section{Introduction}

Rock blasting remains a very important and interesting subject in civil and mining engineering. In particular, the numerical modeling of rock blasting has been a subject of intense study as it provides a useful tool to complement experimental work. Potyondy et al. [1] used $P F C^{3 D}$,

A. Fakhimi

hamed@nmt.edu

1 Department of Mineral Engineering, New Mexico Tech, Socorro, NM 87801, USA a 3-dimensional discrete element program, to simulate rock fragmentation. The explosion was modeled as a time-varying pressure applied at the edge of a cylindrical region 3 times the diameter of the original borehole, to account for the region of crushed rock which would develop around the borehole. Minchinton and Lynch [2] used the combined finite element-discrete element program $\mathrm{MBM}^{2} \mathrm{D}$ to model rock fragmentation and heave in the blasting process. Both stemmed and un-stemmed bench blasts were simulated, and the authors were able to study the effect of a free face on the fragmentation and heaving. Wang et al. [3] developed a cross-format centered finite difference procedure to study a problem involving spalling in a rock plate from an explosive, and compared their results to an LS-DYNA simulation. The AUTODYN 2D computer program was utilized by Zhu et al. [4] to model rock fracturing in a cylindrical specimen with the blast hole located at its center. The authors investigated the effects of different coupling materials placed between the explosive charge and the rock. Ma and An [5] implemented the Johnson-Holmquist model in the LS-DYNA computer program to simulate fracture control techniques in rock. In an attempt to provide some practical tools for rock engineers, Wei et al. [6] used ANSYS-LSDYNA in a parametric study of loading density, rock mass rating, and weight of charge on rock mass damage in underground explosions. Recently, Onederra et al. [7] used a fully coupled gas flow-lattice model to study blast induced damage in rock. While their approach seems to be promising in capturing some features of dynamic rock fracture, due to the confidentiality of their study, they were not able to provide details of their research work.

An important contribution in the field of rock blasting is the project "Hybrid Stress Blast Model" (HSBM) that has resulted in a hybrid code (Blo-Up) that includes blasting processes such as non-ideal detonation to muck pile formation [8]. The developed code (Blo-Up) has demonstrated 
important capabilities in simulating different features of rock blasting, such as burden velocity and displacement observed in the experiments [9].

The above literature review demonstrates that substantial progress has been made in the numerical simulation of blasting. Nevertheless, it appears that there is not yet a robust numerical model to accurately simulate gas flow within the induced micro- and macro-cracks in rock.

In addition to numerical simulations, some lab and field tests have been performed to study the contributions to induced rock damage during the process of blasting. Notable work was conducted by Kutter and Fairhurst [10], who tried to separate the shock effect from the gas expansion effect in rock blasting using small-scale dynamic and static tests on rock and plexiglass samples. They concluded that both the strain wave and gas pressure have important roles in rock fragmentation during the blasting process. Brinkmann [11] separated the strain wave and gas effects by using stainless steel tubes in blast holes, which prevented gas from entering into the damaged rock. Based on his tests results, he suggested that break out is controlled by the gas penetration while the fragment sizes are governed by the strain wave. Similarly, Olsson et al. [12] used a steel liner to isolate the gas during their blast testing. They found that the shock wave is mostly responsible for creating cracks in the rock and the gas pressure moves and separates the already-formed blocks. Other attempts in separating the shock wave and gas effects, by using a copper liner, have been reported in [13, 14]. In particular, it was shown that initial micro-structure and defects can have substantial effects on the post-blast fracture densities. Furthermore, the authors in $[13,14]$ emphasized on the lack of a proven numerical code that can handle both dynamic rock fracture and gas penetration into the shockinduced cracks. One objective of this paper is to introduce a computer code that can handle the issue of gas penetration and flow within the dynamically induced micro- and macro-cracks. To understand the rock blasting fragmentation and swelling issues in sublevel caving, Johansson [15] performed small scale blasting on $140 \mathrm{~mm}$-diameter cylinders of magnetic mortar. The cylinders were confined using different aggregates. The effect of explosive energy and confining pressure on the fragment size distribution were investigated in his study.

Smoothed particle hydrodynamics (SPH) was originally developed in the field of astrophysics [16], but the simplicity and Lagrangian nature of the method encouraged scientists and engineers to quickly apply and diversify its applications to fluid and solid mechanics problems [17]. In many applications, it is convenient to combine SPH with another method, such as the finite element (FEM) or discrete element method (DEM). Combining SPH with FEM can be accomplished by placing the smoothed particles closest to the finite element mesh on a grid and using grid stiffness to transfer forces between the particles and mesh [18]. A method that is better-suited to situations in which the smoothed particles are simulating a fluid is to apply a "penalty force" when smoothed particles impact the finite element grid [19].

The newly-implemented smoothed particle hydrodynamic (SPH) model in the two-dimensional discrete element-finite element program CA2 has already been introduced by the authors [20]. The purpose of this paper is to introduce a more accurate model for interaction of the SPH gas particles with the bonded particles, which prevents the unphysical partial penetration of gas particles into the discrete elements. Additionally, the damage contribution of gas penetration into the induced cracks has been separated from shock effects by means of a copper liner within a borehole. Finally, the effect of rock joints on the induced rock damage is investigated using the numerical model.

\section{Numerical model}

The simulated rock in this paper is Barre granite, which has material properties from [13]; these material properties are: density $=2661 \mathrm{~kg} / \mathrm{m}^{3}$, Young's modulus $=\mathrm{E}_{\mathrm{m}}=41.9 \pm$ 6.6 GPa, uniaxial compressive strength $=161.5 \pm 5.0 \mathrm{MPa}$, Poisson ratio $=v=0.19 \pm 0.04$, and tensile strength $=7.3$ $\mathrm{MPa}$.

\subsection{Discrete element model}

The rock is simulated using a bonded particle model (BPM) discrete element system [21-23]. To capture the interaction between the circular particles (Fig. 1), the equations of motion must be solved together with a constitutive model that relates the contact force with the contact deformation. In this paper, a simple contact bond model is used. The relationships between the incremental contact normal $\left(\Delta F_{n}\right)$ and shear forces $\left(\Delta F_{S}\right)$ with the incremental normal $\left(\Delta U_{n}\right)$ and shear $\left(\Delta U_{S}\right)$ displacements are assumed to be linear as follows:

$$
\begin{aligned}
& \Delta F_{n}=k_{n} \Delta U_{n} \\
& \Delta F_{s}=k_{s} \Delta U_{s}
\end{aligned}
$$

In Eq. $1 \mathrm{a}$ and $1 \mathrm{~b}, k_{n}$ and $k_{s}$ are the normal and shear spring constants. The contact between two particles is assumed to withstand the applied stresses until the limiting load is applied; the contact fails in tension or shear if the applied tensile or shear load exceeds the normal bond $\left(n_{b}\right)$ or shear bond $\left(\mathrm{s}_{\mathrm{b}}\right)$ of the contact. A failed contact that is under the compressive normal load is assumed to follow a Coulomb frictional behavior with a friction coefficient of $\mu$. In this situation the contact can carry a maximum shear force based on equation (2): 


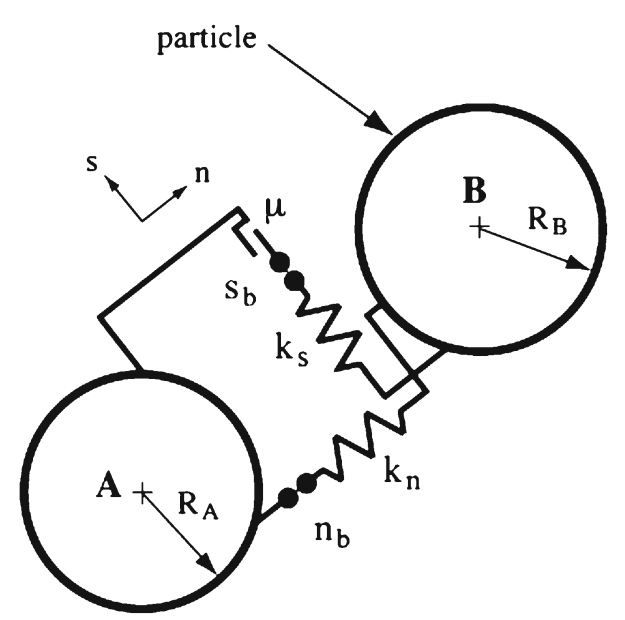

Fig. 1 Interaction of two circular particles (disks) in the discrete element numerical model

$F_{s}^{(\max )}=\mu F_{n}$

The $F_{n}$ parameter in Eq. 2 is the compressive normal contact force. The updated contact forces at any time step in the numerical simulation are used in the equations of motion to obtain the new position of the particles. More details about these equations in discrete element simulation of geomaterials can be found in [21-23].

\subsection{Test set-up and calibration}

The radii of the discrete element circular disks ranged from 0.34 to $0.51 \mathrm{~mm}$. The user-changeable micro-parameters in CA2 (normal and shear bond, normal and shear stiffness, and residual friction coefficient) were adjusted to create a numerical specimen with the desired strength and stiffness listed above; the calibration process was the same as that described in [21]. After calibration, the simulated rock had the following micro-parameters: normal bond $\left(n_{b}\right)=10.5 \mathrm{kN} / \mathrm{m}$, shear bond $\left(s_{b}\right)=105 \mathrm{kN} / \mathrm{m}$, normal stiffness $\left(k_{n}\right)=$ $6.2 \times 10^{10} \mathrm{~Pa}$, and shear stiffness $\left(k_{s}\right)=3.54 \times 10^{10} \mathrm{~Pa}$. A friction coefficient of 0.5 between the disks was used in all simulations. Using numerical uniaxial and Brazilian tests, the following parameters were measured for the simulated rock: Young's modulus $=40.1 \mathrm{GPa}$, Poisson ratio $=$ 0.12 , uniaxial compressive strength $=126 \mathrm{MPa}$, and tensile strength $=7.4 \mathrm{MPa}$. As noted in [24], rocks with high uniaxial compressive strength to tensile strength ratios $\left(q_{u} / \sigma_{t}\right)$ are difficult to model using a discrete element system, and compromises often have to be made to one or both of the aforementioned strength parameters. Since the majority of the developed cracks are tensile in the blasting tests, most of the emphasis during the calibration was to obtain a realistic tensile strength, and so rock compressive strength was of less concern in this study.
Considering the p-wave velocity equation [25]:

$C_{p}=\sqrt{\frac{\lambda+2 \mu}{\rho}}$

where $\rho$ is the material density and $\lambda$ and $\mu$ are the Lamé constants:

$\lambda=\frac{E_{m} \cdot v}{(1-2 v) \cdot(1+v)}$

$\mu=\frac{E_{m}}{2(1+v)}$

the p-wave velocity in the Barre granite can be calculated to be $3947.8 \mathrm{~m} / \mathrm{s}$. This wave velocity is used for analysis of wave propagation in the numerical simulations.

PETN was used for the simulated explosive and an SPH model was utilized to simulate the explosive material. The PETN charge was cylindrical in shape, with a charge diameter of $1.65 \mathrm{~mm}$. The heat of detonation was assumed to be $5.73 \mathrm{MJ} / \mathrm{kg}$ [26], which resulted in a total energy of $16.2 \mathrm{~kJ}$ assuming a PETN density of $1320 \mathrm{~kg} / \mathrm{m}^{3}$ and $1 \mathrm{~m}$ length of explosive charge due to the 2-dimensional simulation. The PETN is assumed to turn into gas instantaneously, and the generated gas is assumed to be inviscid and behaving as a calorically-perfect gas whose equation of state is [27]:

$P=(\gamma-1) \rho e$

In Eq. (6), $P$ is the gas pressure, $\rho$ is the density, and $e$ is the internal energy per unit mass. $\gamma$ was set to 3 in all the numerical blasting tests. The gas was simulated by using 2430 smooth particles. The governing equations for the gas flow within the induced rock fractures, and the SPH format of these equations have been discussed in a previous study [20]. Two primary simulation scenarios are studied. In the first scenario, the PETN charge is simply placed within a 5.25 mm-diameter borehole in rock. In the second scenario there is a copper ring of $0.6 \mathrm{~mm}$ thickness that replaces the edge of the borehole, effectively preventing any gas from penetrating into the rock. In this manner, the effect of gas penetration on crack production can be studied. Figure 2 illustrates the simulated setups.

Considering the fact that rock is a rate-dependent material whose strength can increase when a dynamic load is applied, the strength of the Barre granite was varied in different simulations. The strength was varied by changing the micro parameters $n_{b}$ and $s_{b}$. The rock strength parameters used in this paper are: $n_{b}$ and $s_{b}$ of $10.5 \mathrm{kN} / \mathrm{m}$ and 105 $\mathrm{kN} / \mathrm{m}$, respectively (for Barre granite without taking dynamic strength increase into account), and $n_{b}$ and $s_{b}$ of 2, 5, and 10 times those original values. In an effort to keep terminology simple, the original set of $n_{b}$ and $s_{b}$ values will be referred to 


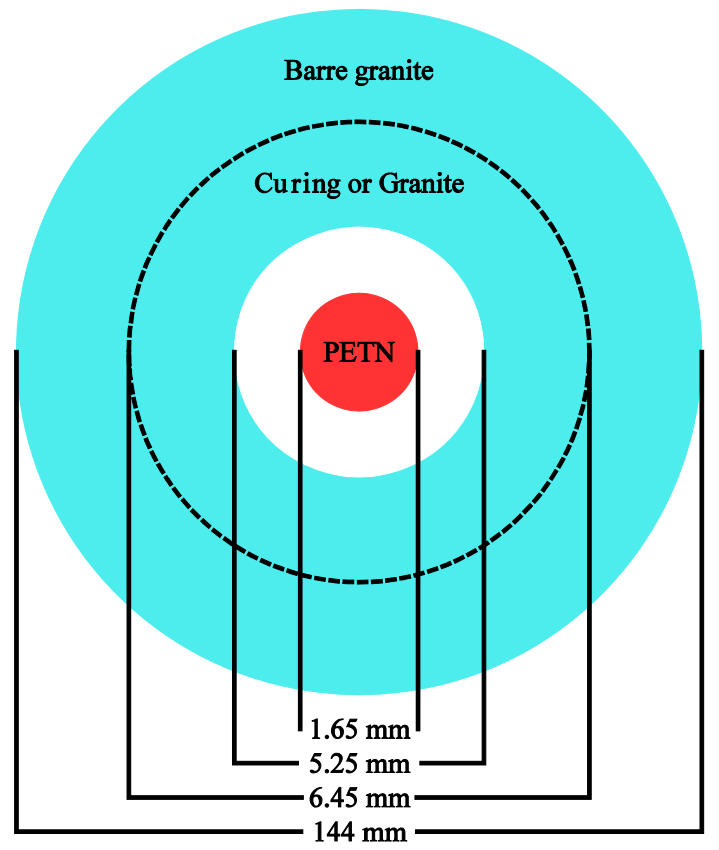

Fig. 2 The simulation configuration (not to scale). The Barre granite specimen is $144 \mathrm{~mm}$ in diameter. The center hole is either a $5.25 \mathrm{~mm}$ diameter borehole in the rock or a $6.45 \mathrm{~mm}$ borehole with a $0.6 \mathrm{~mm}$ thick ring of copper, depending on the particular simulation. The 1.65 $\mathrm{mm}$-diameter PETN charge is placed in the center of the borehole. The space between the PETN and the borehole wall is assumed to be vacuum

as " $1 \mathrm{x}$ strength rock" and the set of $n_{b}$ and $s_{b}$ with, for example, 5 times the original values will be called " $5 \mathrm{x}$ strength rock".

29,411 disks (balls) were used in the case of no finite element grid, and 29,391 disks were used in the simulations with grid (to model the copper ring). The reason for the different number of discrete elements is to account for the lost area due to the copper ring.

For the copper lining, the following static material properties were assumed: ultimate strength $=220 \mathrm{MPa}$, elastic modulus $=119 \mathrm{GPa}$, and Poission's ratio $=0.34$. When copper is under high dynamic loading, the behavior can change dramatically. With this in mind, two types of simulations were run with the copper: one used an elastic model and the other an elastic-perfectly-plastic model. The ultimate tensile strength was used as the yield strength in the elastic-perfectly-plastic model of copper. In all the simulations reported in this paper, a time step of $0.3 \times 10^{-9}$ second was used.

\section{BPM-SPH interaction}

In the previous study, the interaction of gas particles with the discrete elements was assumed to follow a perfectly plastic collision model [20]. Modifications have been made to the SPH implementation in CA2 since the initial paper, many of which were driven by practical experience from running simulations. In particular, an improvement was made to the way in which smoothed particles interact with the discrete elements (balls) or the finite elements. Previously, when a smoothed particle penetrated into a ball, the reaction force was obtained by

$f_{n 1}=\frac{\Delta v_{n}}{\Delta t\left(\frac{1}{m_{D}}+\frac{1}{m_{S P}}\right)}$

in which $\Delta v_{n}$ is the relative velocity along the contact line connecting the smoothed particle to the ball center, $\Delta t$ is the numerical time step, and $m_{D}$ and $m_{S P}$ are the masses of the ball and the smoothed particle, respectively. The contact force $f_{n 1}$ is decomposed into its components along the coordinate axes, and is used in the momentum equations of the ball and smoothed particle. Another approach has been added, which is to handle the interaction of discrete elements with smoothed particles via a "penalty method." In this penalty method, smoothed particles that are trying to penetrate into the discrete elements are pushed back by a linear elastic spring having a force

$f_{n 2}=K_{n} \Delta$

in which $K_{n}$ is the spring constant and $\Delta$ is the amount that the smoothed particle has penetrated into the discrete element (or finite element). The unified approach used in the current version of CA2 consists of combining Equations 7 and 8 as follows:

$f_{n}=\max \left(f_{n 1}, f_{n 2}\right)$

This approach appears to be more effective, as it not only prevents major penetration of smoothed particles into rock grains during the period of initial impacts (through Eq. 7), but also helps to prevent the small penetrations at later times when the particles' momenta are small (through Eq. 8). In reality, depending on the values of the numerical time step and the parameter $k_{n}$, a smoothed particle can still penetrate slightly into a ball, but this penetration should be limited to a very small value when compared to an internal length of the physical problem; a penetration of 2 to $5 \%$ of the ball radius should be acceptable. Figure 3 shows the improvement in program performance after this change has been implemented. The small red particles show the SPH gas particles while the discrete elements are shown with the larger circles. Unphysical partial penetration of smoothed particles within the discrete elements is no longer observed with the new program. 
Fig. 3 Comparison of the old (left) and new (right) contact algorithm applied to contacts between smoothed particles and discrete elements. The old method uses Eq. 7, whereas the new method uses Eq. 9, a combination of Eqs. 7 and 8. In the new method, there is no observed penetration of smoothed particles into discrete elements
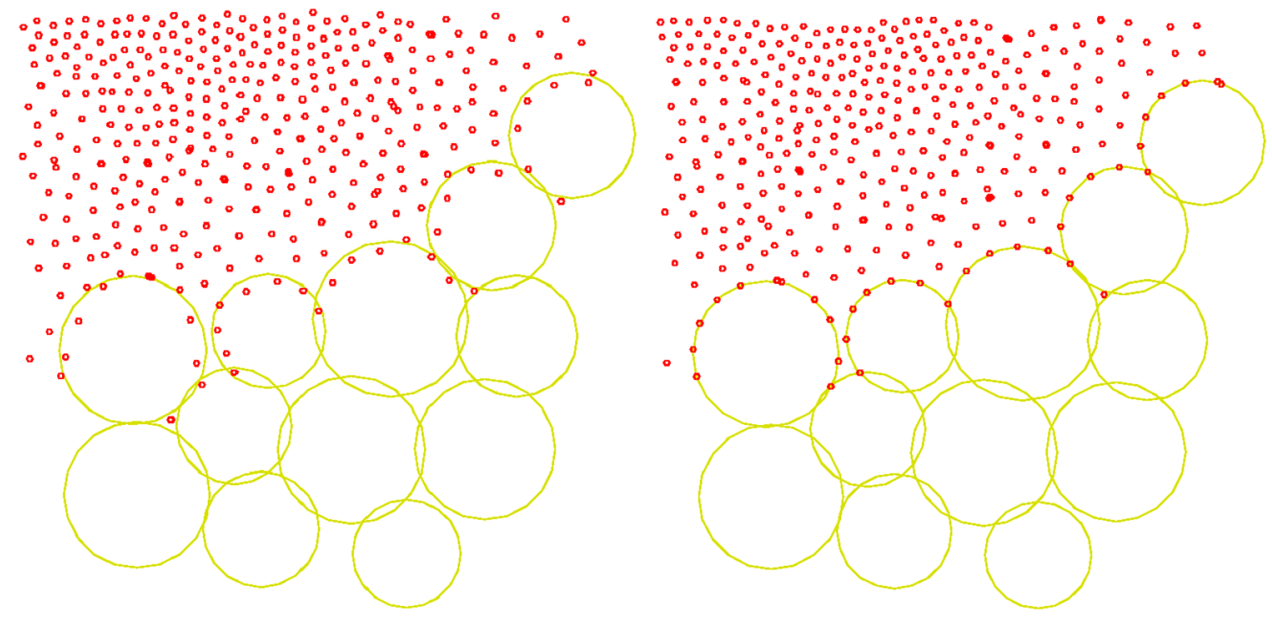

As mentioned before, a time step of $0.3 \times 10^{-9}$ second was used for the numerical simulations in this paper. The limitation on the time step in CA2 is due to the fact that the governing equations are solved using an explicit numerical technique; using a time step that is too large results in numerical instability and divergence of the solution. The maximum time step that can be used is related to the lumped mass of the finite element nodal points and balls (discrete element particles), and the stiffness associated with these nodal points and balls [28]. The same principle applies to the interaction between a smoothed particle and a ball; their masses and the $k n$ parameter in Eq. (8) are used to calculate the critical time step. The critical time steps for the finite element grid, discrete elements, interaction of smoothed particles and balls, and that for the smoothed particles [17] are compared and the minimum one is chosen. This minimum time step is then reduced by a factor of safety to assure convergence of the solution. In CA2, in addition to the automatic calculation of the critical time step by the program, the user can dictate its own time step for the situations that a unique time step is to be used for all the simulated problems.

Note that the value of $k_{n}$ in Eq. (8) not only can change the time step, it can affect the reaction force and the amount of the penetration of the smoothed particles into the balls. The parameter $k_{n}$ acts as a penalty parameter. The value of $k_{n}$ should be small enough to prevent too much restriction on the time step. At the same time, $k_{n}$ must be large enough to prevent noticeable penetration of smoothed particles into the balls. In the example shown in Fig. 3 and all the blasting numerical simulations in this paper, the $k_{n}$ value was chosen to be the same as the ball normal stiffness for the discrete elements.

\section{Verification of the contact model}

To verify the appropriateness of the new contact model for interaction of smoothed particles and balls or finite elements, the drag force on a cylinder that moves along a wind tunnel was analyzed. The stationary gas in the wind tunnel was assumed to have the following properties: $\rho_{\infty}=$ initial gas density $=1 \mathrm{~kg} / \mathrm{m}^{3}, P_{\infty}=$ initial gas pressure $=10^{5} \mathrm{~Pa}$, and $\gamma$ (in Eq. 6) $=1.4$. Using these gas parameters, the sound speed $\left(a_{\infty}=374.2 \mathrm{~m} / \mathrm{s}\right)$ can be obtained from the following equation:

$a_{\infty}=\sqrt{\frac{\gamma P_{\infty}}{\rho_{\infty}}}$

The hollow cylinder is modeled by finite element and has an external radius of $0.1 \mathrm{~m}$. The cylinder is assumed to be elastic with an elastic modulus of $21 \mathrm{GPa}$, a Poisson's ratio of 0.1 , and a density of $2000 \mathrm{~kg} / \mathrm{m}^{3}$. Three different velocities $\left(V_{\infty}\right)$ for the cylinder $(804.5,927.9,1212.3 \mathrm{~m} / \mathrm{s})$, consistent with those in the experimental study [29] were used. The gas was modeled by using 38,380 smoothed particles. Figure $4 \mathrm{a}$ shows the finite element discretization of the cylinder together with the smoothed particles for the situation that the cylinder velocity is $1212.3 \mathrm{~m} / \mathrm{s}$. The bow shock in front of the cylinder together with the contours of gas density around the cylinder is shown in Fig. 4a. Note that even though the speed of cylinder is very high (supersonic velocity), no smoothed particle has been able to penetrate within the finite element domain. This indicates the accuracy of the contact model. The drag coefficient was obtained from the following equation [27]:

$C_{d}=\frac{D}{\frac{1}{2} \rho_{\infty} V_{\infty}^{2}(2 R)}$

in which $D$ is the drag force and $R$ is the radius of the cylinder. The drag forces for different cylinder velocities were obtained from the CA 2 computer program. Figure $4 \mathrm{~b}$ depicts the variation of drag force versus the simulation time. The numerical analysis was continued until a steady state drag 
Fig. 4 The numerical results of gas-cylinder interaction, a the hollow cylinder, smoothed particles, and density contours of the gas $\left(\mathrm{kg} / \mathrm{m}^{3}\right)$ with the developed bow shock in front of the cylinder, $\mathbf{b}$ the gas force imposed on the cylinder versus the simulation time
A

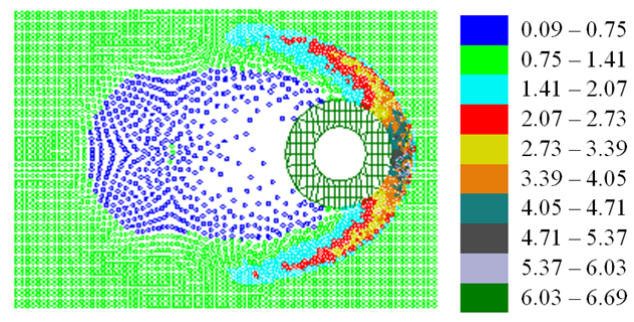

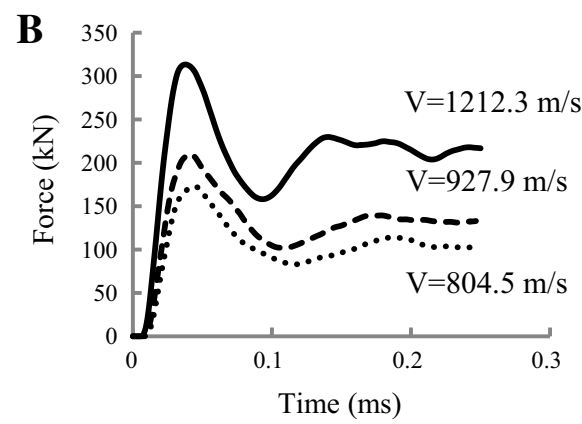

Table 1 Comparison of the physical and numerical data for drag force and drag coefficient for a cylinder moving with a constant speed through an initially stationary gas

\begin{tabular}{lllll}
\hline$V_{\infty}(\mathrm{m} / \mathrm{s})$ & $\begin{array}{l}M_{\infty}=V_{\infty} / a_{\infty} \\
\text { (Mach number) }\end{array}$ & $\begin{array}{l}\text { Numerical drag } \\
\text { force }(\mathrm{D}) \text { in } \mathrm{kN}\end{array}$ & $\begin{array}{l}\text { Numerical drag } \\
\text { coefficient }\left(C_{d}\right)\end{array}$ & $\begin{array}{l}\text { Experimental drag } \\
\text { coefficient }\left(C_{d}\right)\end{array}$ \\
\hline 804.5 & 2.15 & 102 & 1.57 & 1.23 \\
927.9 & 2.48 & 134 & 1.55 & 1.28 \\
1212.3 & 3.24 & 221 & 1.5 & 1.22 \\
\hline
\end{tabular}

force on the cylinder was obtained. Table 1 summarizes the results. The drag coefficient $\left(C_{d}\right)$ from the numerical model can be compared with those from experimental tests reported by Hall [29]. The results are in fair agreement considering the simplifications in the equation of state of the gas, non-smoothness of the surface of the cylinder (due to the finite element discretization), assumption of inviscid flow, and the end effects in the experimental tests (2D cylinder in the numerical model versus 3D cylinder in the physical tests). It is interesting to note that the approximate drag coefficient based on Newtonian theory is 1.33 that suggests an intermediate value between the numerical and physical tests data. The results of this section confirm the usefulness of the proposed interaction model for the smoothed particles with the balls or finite element grid.

\section{Crack propagation and gas penetration}

Crack propagation is tremendously affected by the strength of the rock (or by the strength of the explosive charge). Figures. 5 and 6 show the number of cracks and crack pattern that develops in the 1x strength Barre granite. A crack in the CA2 program is a line perpendicular to the line connecting the centers of the two balls involved with the damaged contact. The simulated problem is shown in Fig. 2 with no copper liner. As seen in Fig. 5, the primary shock wave reaches the edge of the sample at approximately $19 \mu$ s and causes surface spalling (between points A and B). Knowing that the p-wave velocity is $3947.8 \mathrm{~m} / \mathrm{s}$ in the simulated Barre granite, we can calculate the time that it takes the shockwave to reach the edge of the rock specimen: it is approximately $18 \mu \mathrm{s}$. There is substantial cracking between points $\mathrm{B}$ and $\mathrm{C}$, as the compressive shock wave reflects off the edge of the sample

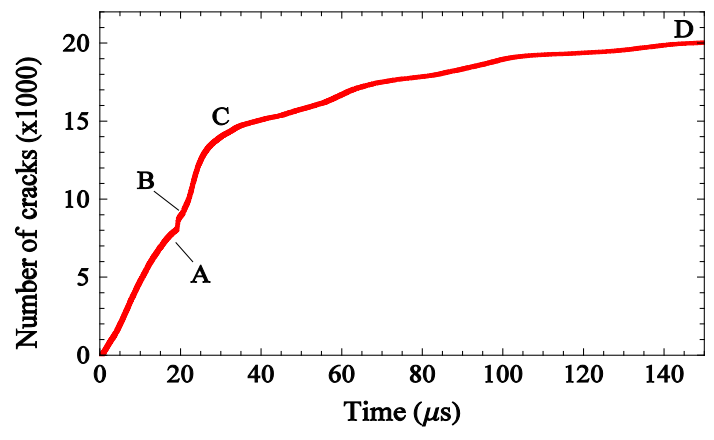

Fig. 5 Number of micro-cracks in the 1x strength Barre granite. The letters denote the locations of pictures in Fig. 6

and becomes tensile and creates further damage as it travels back towards the borehole. Between $\mathrm{C}$ and $\mathrm{D}$, there is a slow increase in damage as the gas continues to push and expand the borehole boundary, and slowly begins to penetrate into the rock surrounding the borehole. Note how the computational model has been able to reproduce the crushed zone around the borehole, tensile redial cracks, and surface spalling. The damaged zones around the borehole are mostly shear cracks (shown in blue), while the radial cracks and surface spalling are due to tensile stresses (shown in red). Considering the fact that it takes about $40 \mu \mathrm{s}$ for the initial shock wave to go forth and back through the specimen, it can be observed from Fig. 5 that most of the induced damages in rock have been due to the effect of shock wave; the role of the penetrating gas is mostly to push the developed rock fragments apart. This is consistent with the experimental observation reported in [12]. Furthermore, the induced damage rate due to the shock wave is much higher than that by the gas penetration effect. This is suggested by the drastic difference in the slopes of the lines $\mathrm{OA}$ and $\mathrm{BC}$ compared to that of line $\mathrm{CD}$. 
Fig. 6 Location of cracks in the 1x strength Barre granite. The letters denote the locations of the pictures in Fig. 5. The yellow region is the discrete elements simulating the rock. The tensile and shear cracks are shown in red and blue, respectively. (Color figure online)
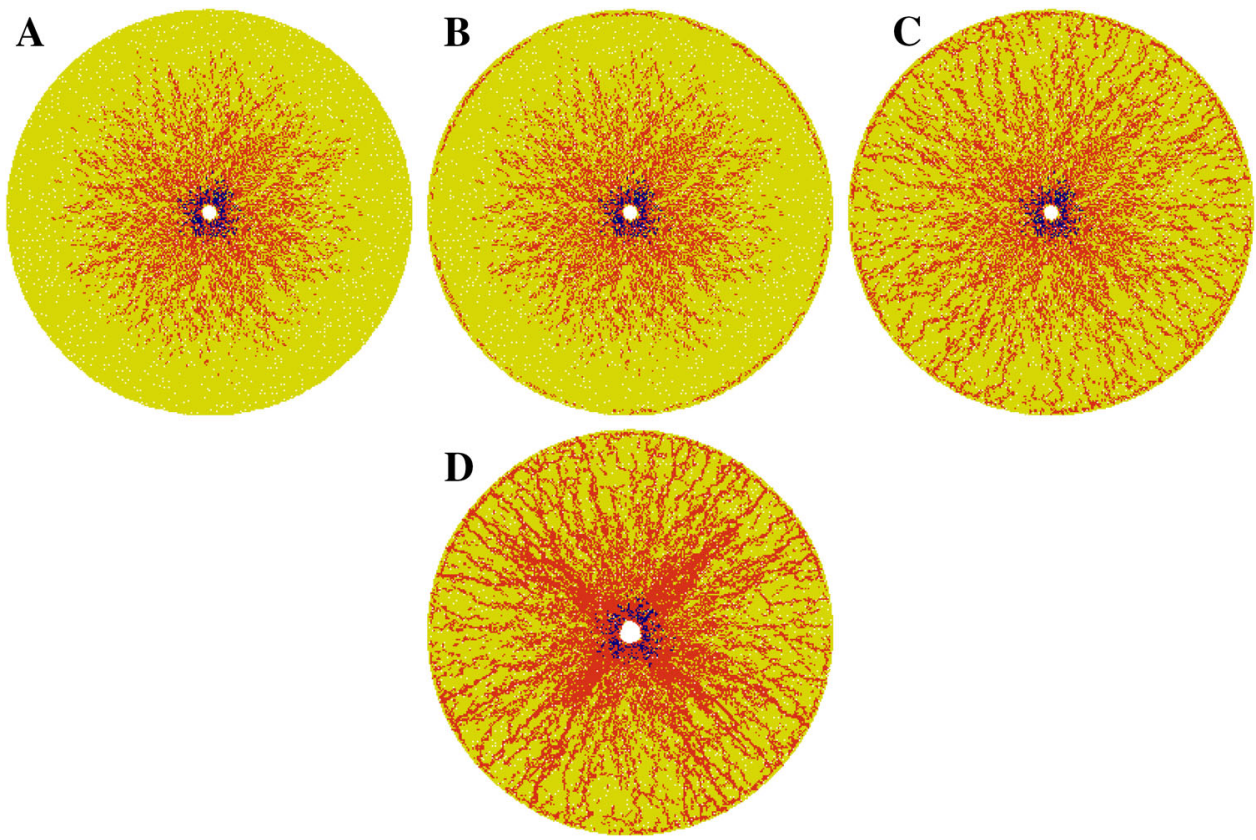

damage in Fig. 9 for 10x strength rock is more localized than the situation for the weaker rock. As a result, the extensive damage and the resulting debris prevent the gas from penetrating within the cracks; the borehole expands with no clear localized gas penetration. On the other hand, less debris is produced in the stronger rock, and the gas is more easily able to penetrate within the induced macro-cracks (Fig. 10). Figures 9 and 10 clearly suggest that excessive amounts of explosive material (in this case for the $1 \mathrm{x}$ rock) can actually prevent gas from penetrating within the induced cracks which is the result of less efficient usage of the explosive material.

\section{Borehole lining}

As mentioned before, lining the borehole with a $0.6 \mathrm{~mm}$-thick ring of copper provides the ability to prevent the gas from penetrating into the rock. This technique is more effective than the strategy of the previous section in regards to separating the effects of shock wave and gas flow. CA2 allows for both elastic and plastic behavior of the copper ring; choosing plastic behavior allows for more energy to be imparted into the rock, but it also results in necking. This necking eventually causes geometrical elements in the finite element grid to become severely distorted, terminating the simulation.

\subsection{Elastic lining}

It is desirable to run a parametric study on the stiffness (Young's modulus) of the copper, because the heat and pressure of detonation can cause the copper to have less stiffness than it would in a static situation. To this end, results for elaswave travel across the rock sample. Notice that the induced 
Fig. 8 Location of cracks in the $5 \mathrm{x}$ strength Barre granite. The letters denote the locations of the pictures in Fig. 7

Fig. 9 Gas penetration (red particles) and the developed damages after $240 \mu \mathrm{s}$ in the $1 \mathrm{x}$ (left) and 10x (right) strength

Barre granite. The region shown is $40 \mathrm{~mm}$ by $40 \mathrm{~mm}$ centered on the borehole. (Color figure online)

Fig. 10 Gas penetration (red particles) and the developed damages after $480 \mu \mathrm{s}$ in the $1 \mathrm{x}$ (left) and 10x (right) strength Barre granite. The region shown is $40 \mathrm{~mm}$ by $40 \mathrm{~mm}$ centered on the borehole. (Color figure online)
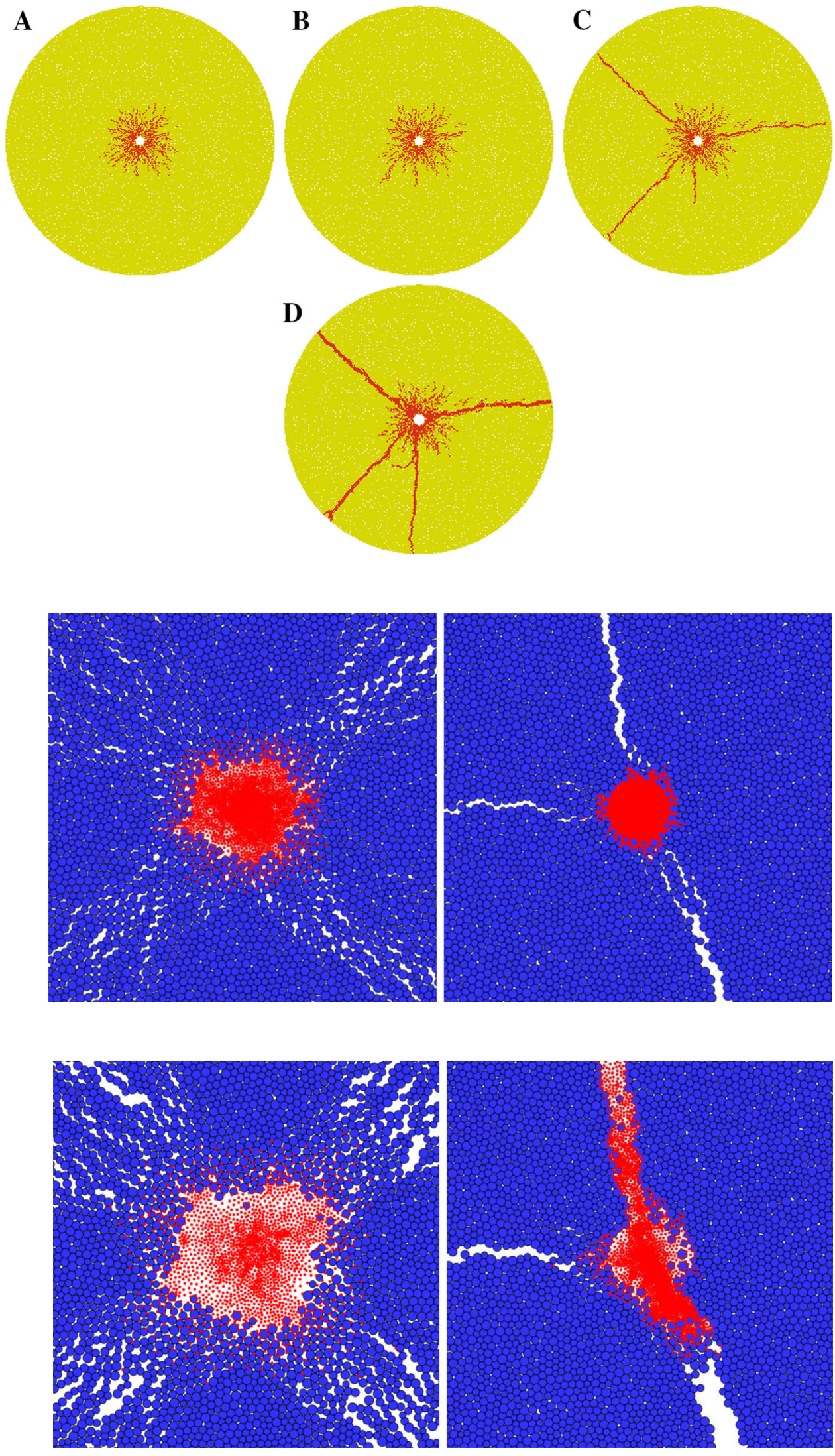


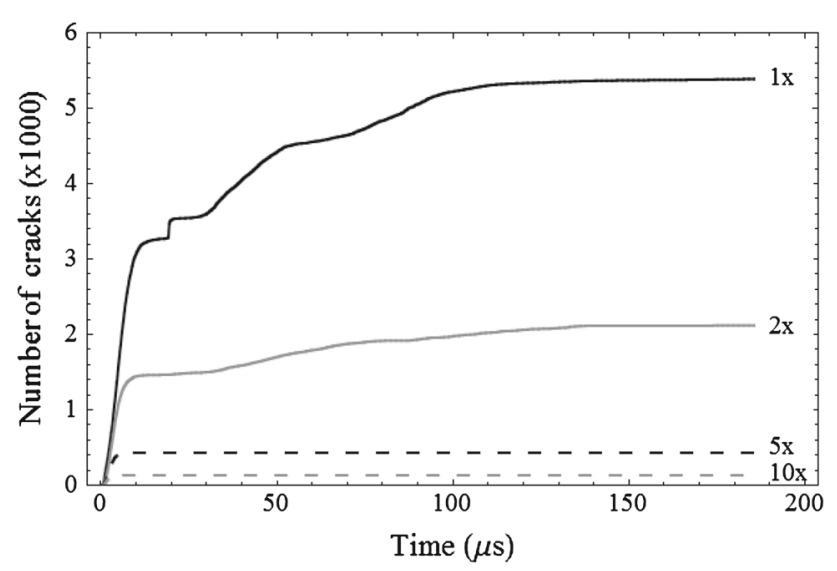

Fig. 11 Number of cracks in the simulated granite with a copper liner with a Young's modulus of $119 \mathrm{GPa}$. The behavior of different rock strengths is shown

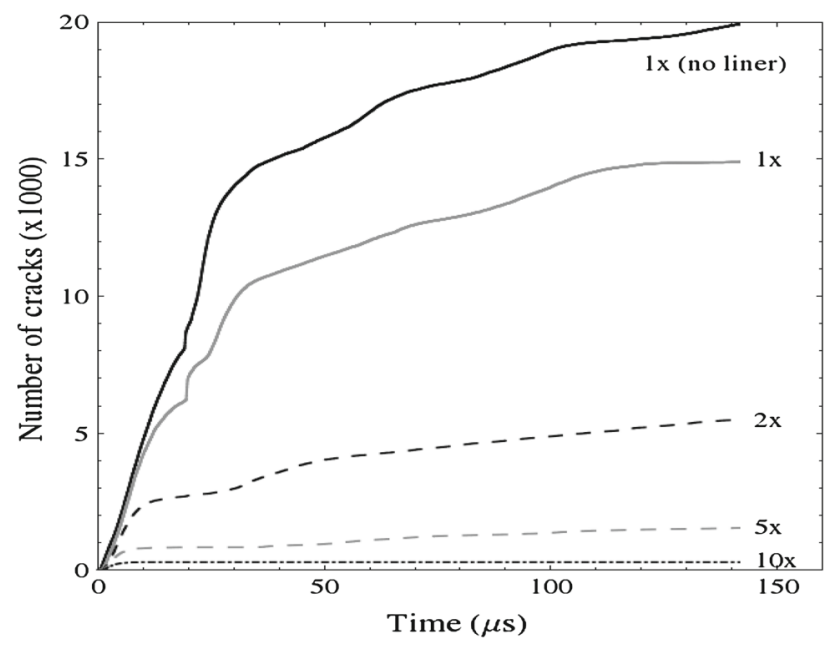

Fig. 12 Number of cracks in the simulated granite with a copper liner with a Young's modulus of $11.9 \mathrm{GPa}$ (one-tenth elastic modulus of copper). The behavior of different rock strengths is shown. The curve for 1x strength rock with no liner (Fig. 5) is shown for comparison as well

tic copper rings having elastic moduli of $119 \mathrm{GPa}$ (Fig. 11) and $11.9 \mathrm{GPa}$ (Fig. 12) are shown for rocks with different strengths. Keeping in mind that the first shock has completely reflected back to the borehole by about $40 \mu$ s, Figs. 11 and 12 support the earlier assertion that a significant amount of cracking occurs merely due to the initial shock effects; this is particularly the case for the stronger rocks.

Alternatively, by comparing the cracking behavior of rock in tests with and without the borehole liner, one can place limits on the amount of influence gas penetration has on crack propagation. The curve for $1 \mathrm{x}$ strength rock with borehole lining in Fig. 12, for example, can be directly compared to Fig. 5 (this figure is included in Fig. 12 for better comparison), and it is apparent that there are around $25 \%$ fewer microcracks when there is a liner surrounding the borehole.

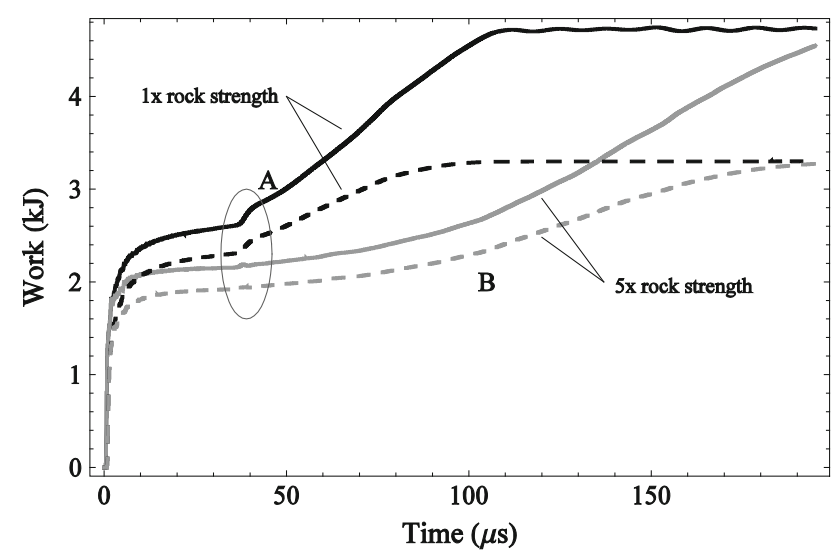

Fig. 13 Work done on the ring with one-tenth stiffness copper and $1 \mathrm{x}$ rock strength and $5 \mathrm{x}$ rock strength. The solid lines denote the work done on the inside of the ring and the dashed lines show the work done on the outside of the ring. The ellipse indicates the approximate point at which the wave returns to the grid, allowing for sudden expansion. The letters "A" and "B" denote the position in time for the pictures in Fig. 14
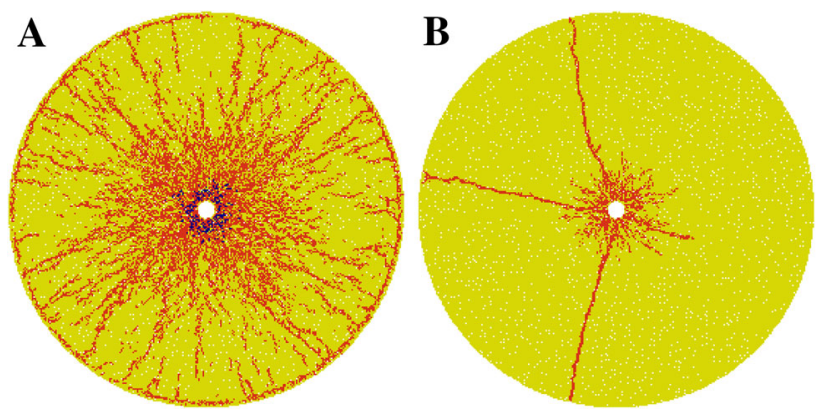

Fig. 14 Crack pattern for the $1 \mathrm{x}$ strength rock $45 \mu$ s after detonation (left) and $5 \mathrm{x}$ strength rock $105 \mu \mathrm{s}$ after detonation (right). In both cases the borehole is lined with a copper ring having $\mathrm{E}_{\mathrm{m}}=11.9 \mathrm{GPa}$. The letters denote the location of these pictures in Fig. 13

\subsection{Energy imparted to grid}

To calculate the work done on the copper grid, the force $\left(F_{i}\right)$ and velocity $\left(v_{i}\right)$ from each liner boundary nodal point are measured around the boundary under study (either the inside of the ring to measure input energy, or the outside of the ring to measure output energy). In either case Eq. (12) is used:

$W=\int \sum_{i=1}^{2} \sum_{j=1}^{N} F_{i}^{j} v_{i}^{j} \Delta t$

In Eq. (12), $i=1,2$ and $j=1, N$ where $\mathrm{j}$ is the number of nodes around the ring. Figure 13 displays the work done on a one-tenth stiffness ring $\left(\mathrm{E}_{\mathrm{m}}=11.9 \mathrm{GPa}\right)$ for the $1 \mathrm{x}$ and $5 \mathrm{x}$ strength rock. There is some interesting behavior in Fig. 13, which occurs at around $100 \mu \mathrm{s}$, and that is the fact that the work curves of the two rings begin to converge. This can be explained by Fig. 14, which shows that in the 1x strength rock there are cracks extending from the center of the borehole to the edge of the sample by $45 \mu \mathrm{s}$. This enables the rock around 
the grid to move away from the grid, and therefore the grid can continue to expand. In the $5 \mathrm{x}$ strength rock, the cracks do not completely extend from the borehole to the sample edge until around $105 \mu \mathrm{s}$, but once these cracks are created, the grid is again able to quickly expand, and then the work input and output energies approach to those of the $1 \mathrm{x}$ strength rock.

Notice that in Fig. 13, the input energy delivered by the gas is always greater than the output energy, which is the energy delivered by the copper liner to the rock specimen. The difference between the input and output energies is the kinetic and elastic strain energies that are absorbed by the lining. Note that for the example studied in this work, the absorbed energy by the liner is about one third of the delivered energy to the rock.

The ellipse in Fig. 13 shows the time at which the reflected shock wave returns to the copper ring. Due to the tensile nature of the reflected wave, the wave pulls back the grid allowing for a rapid rise in the work-rate of the grid at around $40 \mu \mathrm{s}$.

\subsection{Plastic grid}

In this section, the copper ring is modeled as an elasticperfectly plastic material. A drawback to using an elasticperfectly-plastic material is that in the simulations presented here, the finite element grid breaks down under the load after less than $100 \mu$ s of simulated time after detonation, restricting studies to the early period after detonation.

Figures 15, 16, 17 and 18 show the results of the numerical test when an elastic-perfectly-plastic ring is surrounded by the $1 \mathrm{x}$ strength rock. Two yield strengths of $440 \mathrm{MPa}$ and 880 MPa were chosen as a parametric study. These values are two and four times the static copper strength. Figure 15 shows the number of cracks in the rock for these two situations, while Fig. 16 shows the work done on the ring in both cases. In Fig. 15, the curve for $1 \mathrm{x}$ strength rock with no liner (Fig. 5) is shown as well. Figure 17 is a picture of the induced cracks in the specimens.

Figure 16 shows a different behavior from the elastic ring in Fig. 13. Here, there is no gradual convergence with a particular value within the time frame of analysis, as the plastic ring continues to absorb more energy and to expand. The necking of the grid and subsequent halting of the simulation due to bad mesh geometry (see Fig. 18) prevented the simulation from being run further forward in time.

One difference between the application of plastic ring and both the elastic and no-grid situations is the sheer amount of spalling that occurs. Figure 15 shows this as a near-doubling in the number of cracks at around $20 \mu \mathrm{s}$, while Fig. 17 graphically indicates the presence of a double-spall zone near the specimen's surface in both the cases of $440 \mathrm{MPa}$ yield strength and $880 \mathrm{MPa}$ yield strength copper. This indicates

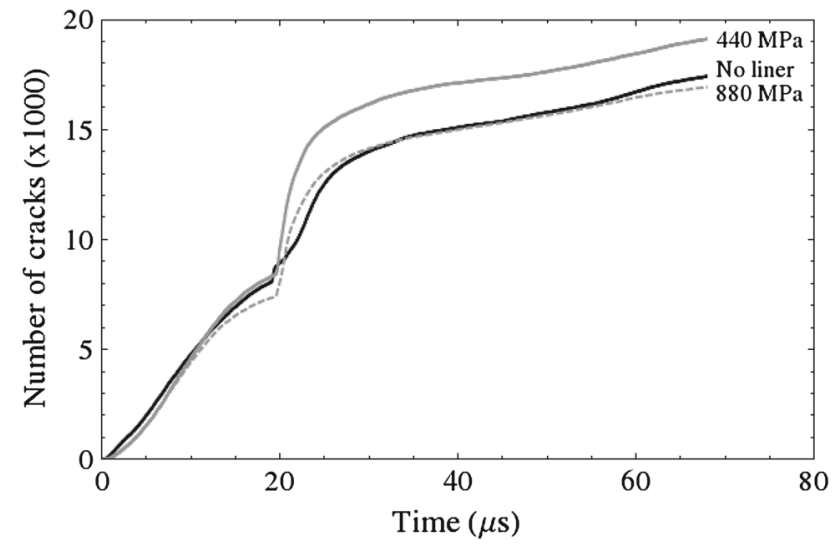

Fig. 15 Number of cracks in the simulated granite for $1 \mathrm{x}$ strength rock and elastic-perfectly-plastic copper ring with yield strengths of $440 \mathrm{MPa}$ and $880 \mathrm{MPa}$. The curve for $1 \mathrm{x}$ strength rock with no liner is shown as well

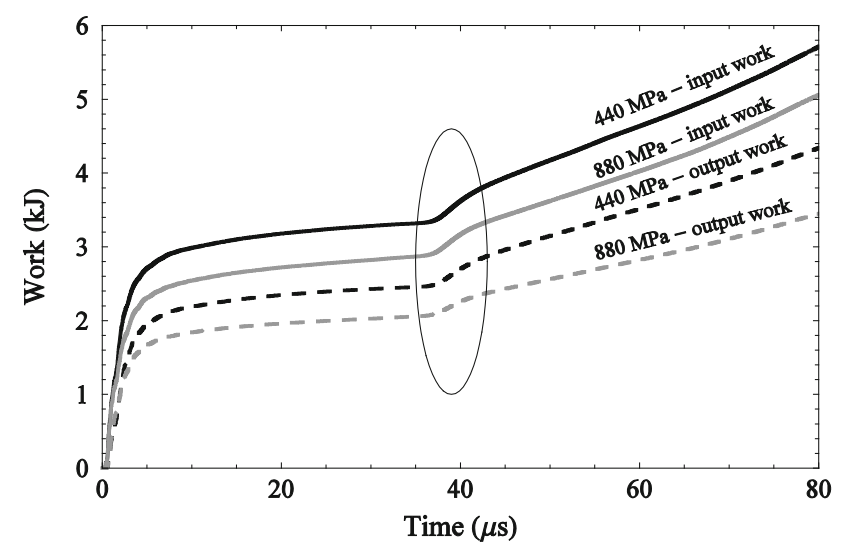

Fig. 16 Work done on the ring surrounded by $1 \mathrm{x}$ strength rock and elastic-perfectly-plastic copper ring with yield strength of $440 \mathrm{MPa}$ and $880 \mathrm{MPa}$

how attempts in separating the shock wave and gas penetration effects by a liner can be challenged by the cushion effects that a plastic ring can provide resulting in double spall zones. As a consequence of more extensive surface spalling, the numerical model suggests greater induced cracks in the rock for the situation with a liner (with the copper yield strength of $440 \mathrm{MPa}$ ) compared to the no liner situation (Fig. 15). Notice that in the case of plastic ring like the situation with an elastic ring, upon the return of the shock wave, the rates of the input and output work show a sudden change indicated with an ellipse in Fig. 16.

\section{Effect of joints on rock damage}

CA2 allows joint sets to be placed in the discrete element rock. This is a powerful tool that allows for the study of the role that rock imperfections can play on blasting damage. Figure 19 presents a schematic of the joint set configuration 

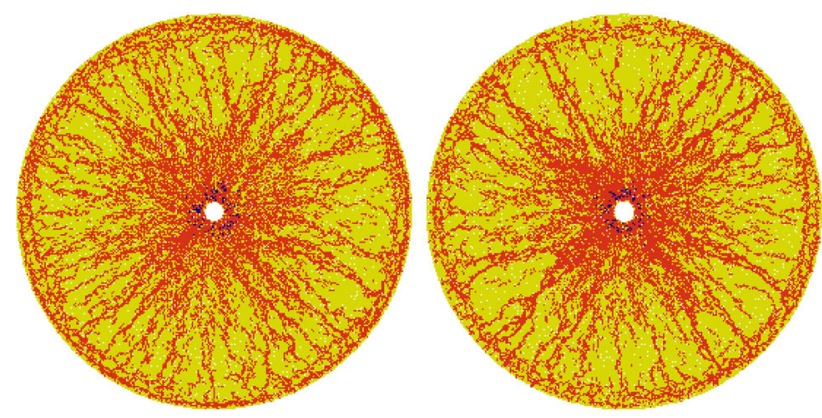

Fig. 17 Crack pattern for the 1x strength rock and the elastic-perfectlyplastic copper ring with yield strength of $440 \mathrm{MPa}$ after $83 \mu \mathrm{s}(l e f t)$ and yield strength of $880 \mathrm{MPa}$ after $129 \mu \mathrm{s}$ (right)

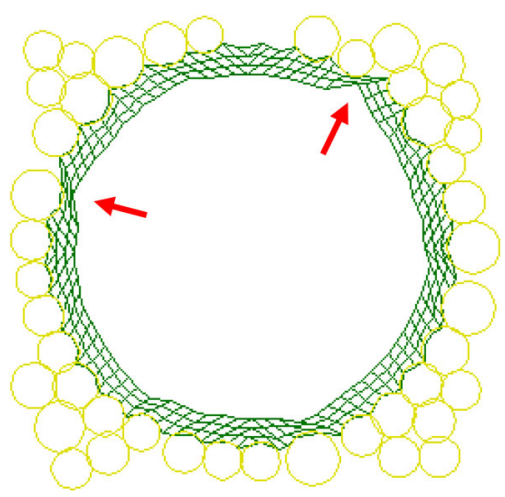

Fig. 18 Necking due to shear bands observed in a particular simulation. The copper ring is the green grid, and the necking locations are indicated by the red arrows. The yellow circles are the discrete elements simulating the innermost part of the rock specimen. The SPH gas particles within the borehole are not shown. (Color figure online)

used in this paper; two joint sets are used with each joint set having two joints that are spaced $72 \mathrm{~mm}$ apart and are offset from the borehole by $36 \mathrm{~mm}$. In this way, a central area of intact rock $72 \mathrm{~mm}$ by $72 \mathrm{~mm}$ has been created. One goal of this configuration is to determine whether rock damage will extend beyond the central region of intact rock. In this study, $5 \mathrm{x}$ strength intact rock was simulated, and on the joints, the discrete element micro-parameters $k_{n}, k_{s}, n_{b}$, and $s_{b}$ were reduced to $1 / 10$ of the values for $1 \mathrm{x}$ strength rock. In this way, the joints were made to be weaker and softer than the surrounding rock.

Figure 20 shows the damaged specimen at 15 and $270 \mu$ s. Notice the induced microcracks along the joints that have been created due to the shock effects at $15 \mu \mathrm{s}$. After $270 \mu \mathrm{s}$, it is evident that the damage is primarily confined to the inner area of rock within the joints; the joints have causes most of the shock wave energy to be confined within the region surrounded by the joints making this region the mostly damaged region. Comparison of the damaged zones at 15 and $270 \mu$ s suggests that most of the microcracks have been the result of the propagating shock wave. This observation is

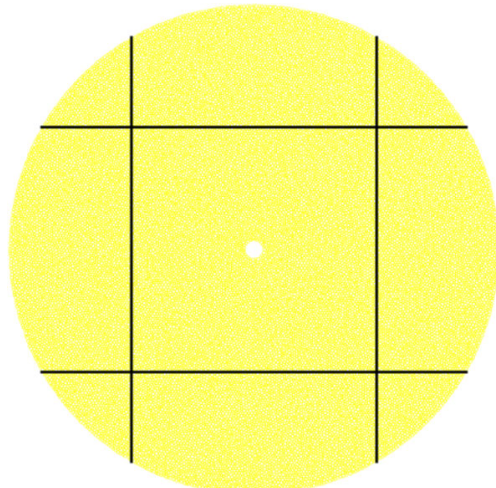

Fig. 19 The numerical specimen with the two joint set orientations
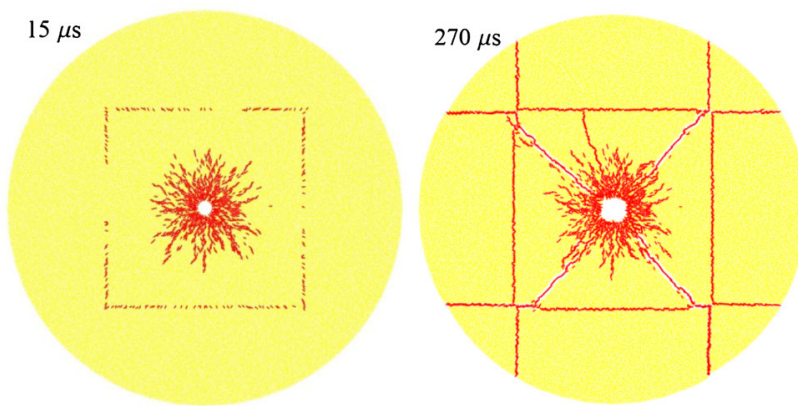

Fig. 20 Two images illustrating the pattern of cracking that occurred in the jointed rock specimen. At $15 \mu$ s there is a crushed zone with some damages along the joints. After $270 \mu \mathrm{s}$, it is evident that most of the damage is confined to the central area of the rock sample confined by the joints

consistent with the situations studied for the intact rock in the previous examples.

\section{Conclusion}

The recently-implemented SPH model in the CA2 computer program has enabled numerical studies to be performed on the effects of blasting on rock. In particular, CA2's ability to combine FEM, DEM, and SPH has been exploited to simulate a wide range of scenarios that can, in turn, be compared to actual experimental results. The developed model is capable of simulating the induced cracks as well as the gradual infiltration of gas into the cracks. A new contact model for the interaction of discrete particles and smoothed particles was also introduced. This model seems to be effective in preventing partial penetration of smoothed particles into discrete elements. Several numerical tests were conducted to study the relative contributions of the shock wave and gas penetration on rock damage. The numerical results, consistent with experimental observations reported in the literature, suggest 
that the effect of the shock wave is to create the majority of the cracks in the specimen. The slowly-operating contribution of the gas is mostly to push the generated rock fragments, due to the early shock effects, farther apart. In the simulation of rock blasting with a liner, it was shown that depending on the type of constitutive behavior and yield strength of the copper lining, different regimes of rock fracturing can be observed. In particular, the use of an elastic-perfectly-plastic copper lining can cause double and multiple rock surface spalling. This observation challenges any physical experiment that attempts to separate the effect of gas flow and shock wave by means of a liner in the blast hole, since the shape of the propagating shock wave can be affected by the liner. Finally, the simulation results for a rock specimen with joints suggest that the joints can act as energy barriers, causing localized rock damage.

\section{References}

1. Potyondy D, Cundall P, Sarracino R (1996) Modeling of shock- and gas-driven fractures induced by a blast using bonded assemblies of spherical particles. In: Mohanty B (ed) Rock fragmentation by blasting. A.A. Balkema, Rotterdam, pp 55-62

2. Minchinton A, Lynch P (1996) Fragmentation and heave modeling using a coupled discrete element gas code. In: Mohanty B (ed) Rock fragmentation by blasting. A.A. Balkema, Rotterdam, pp 71-80

3. Wang Z, Yong-chi L, Wang J (2008) Numerical analysis of blastinduced wave propagation and spalling damage in a rock plate. Int J Rock Mech Min Sci 45:600-608

4. Zhu Z, Mohanty B, Xie H (2007) Numerical investigation of blasting-induced crack initiation and propagation in rocks. Int $\mathrm{J}$ Rock Mech Min Sci 44:412-424

5. Ma G, An X (2008) Numerical simulation of blasting-induced rock fractures. Int J Rock Mech Min Sci 45:966-975

6. Wei X, Zhao Z, Gu J (2009) Numerical simulations of rock mass damage induced by underground explosion. Int J Rock Mech Min Sci 46:1206-1213

7. Onederra IA, Furtney JK, Sellers E, Iverson S (2013) Modeling blast induced damage from a fully coupled explosive charge. Int J Rock Mech Min Sci 58:73-84

8. Sellers E, Furtney J, Onederra I, Chitombo G (2012) Improved understanding of explosive-rock interactions using the hybrid stress blasting model. J S Afr Inst Min Metall 112:721-727

9. Wimmer M, Nordqvist A, Ouchterlony F, Nyberg U (2013) Burden movement in confined drift wall blasting tests studied at the LKAB Kiruna SLC mine. In: Singh, Sinha (eds) Rock fragmentation by blasting. Taylor \& Francis Group, London
10. Kutter HK, Fairhurst C (1970) On the fracture process in blasting. Int J Rock Mech Min Sci 8:181-202

11. Brinkmann JR (1990) An experimental study on the effects of shock and gas penetration in blasting. Fragblast 90, Brisbane, 55-66

12. Olsson M, Nie S, Bergqvist I, Ouchterlony F (2002) What causes cracks in rock blasting? Fragblast 6(2):221-233

13. Dehghan Banadaki MM (2010) Stress-wave induced fracture in rock due to explosive action. Ph.D. Thesis. University of Toronto

14. Mohanty B, Dehghan Banadaki MM (2009) Characteristics of stress-wave induced fractures in controlled laboratory-scale blasting experiments. In: Wang X (ed) Proceedings $2^{\text {nd }}$ Asian-Pacific symposium on Blasting Technique. Metallurgical Industry Press, Beijing, pp 43-49

15. Johansson D (2008) Fragmentation and waste rock compaction in small scale blasting. Licentiate Thesis, Department of Civil, Mining and Environmental Engineering, Lulea University of Technology, Sweden

16. Lucy LB (1977) Numerical approach to testing the fission hypothesis. Astron J 82:1013-1024

17. Liu G, Liu M (2003) Smoothed particle hydrodynamics: a meshfree particle method. World Scientific Publishing Co, Singapore

18. Johnson G (1994) Linking of Lagrangian particle methods to standard finite element methods for high velocity impact computations. Nucl Eng Des 150:265-274

19. Campbell J, Vignjevic R, Libersky L (2000) A contact algorithm for smoothed particle hydrodynamics. Comput Methods Appl Mech Eng 184:49-65

20. Fakhimi A, Lanari M (2014) DEM-SPH simulation of rock blasting. Comput Geotech 55:158-164

21. Fakhimi A, Villegas T (2007) Application of dimensional analysis in calibration of a discrete element model for rock deformation and fracture. Rock Mech Rock Eng 40:193-211

22. O'Sullivan C (2011) Particulate discrete element modelling, a geomechanics perspective. Spon Press, London and New York

23. Rojek J, Onate E, Labra C, Kargl H (2011) Discrete element simulation of rock cutting. Int J Rock Mech Min Sci 48(6):996-1010

24. Fakhimi A (2004) Application of slightly overlapped circular particles assembly in numerical simulation of rocks with high friction angles. Eng Geol 74:129-138

25. Goodman R (1989) Introduction to rock mechanics, 2nd edn. Wiley, New York

26. Dobratz B, Crawford P (1985) LLNL explosives handbookproperties of chemical explosives and explosive simulants. University of California, Livermore, California

27. Anderson JD (2003) Modern compressible flow, 3rd edn. McGrawHill, New York

28. Itasca Consulting Group (1999) PFC3D, particle flow code in 3 dimensions manual. Minneapolis, Minnesota

29. Hall RT (1960) The lift and drag on a rotating cylinder in supersonic crossflow, NAVORD Report 6093, Aerodynamic Research Report 29, US Naval Ordnance Laboratory, White Oak, Maryland 